\title{
Ultraviolet sensing properties of polyvinyl alcohol-coated aluminium-doped zinc oxide nanorods
}

\author{
KANCHAN SAXENA*, AMIT KUMAR, NISHANT MALIK, PRAMOD KUMAR and V K JAIN \\ Amity Institute of Advanced Research and Studies (Materials and Devices), Amity University, Noida, 201 303, India
}

MS received 6 September 2012; revised 18 February 2013

\begin{abstract}
Undoped and aluminium (Al)-doped zinc oxide ( $\mathrm{ZnO}$ ) nanorods have been synthesized by electrochemical route. The synthesized materials have been characterized by X-ray diffraction, UV-visible spectrometer and scanning electron microscope. The Al-doped $\mathrm{ZnO}$ nanorods have been coated with polyvinyl alcohol. Currentvoltage characteristics have been investigated in dark and under UV-light illumination. Aluminium doping in ZnO increase its electrical conductivity and further polyvinyl alcohol coating on Al-doped ZnO increase UV sensitivity of the material. Response and recovery time of Al-doped $\mathrm{ZnO}$ and PVA-coated Al-doped $\mathrm{ZnO}$ nanorods have been recorded. PVA-coated $\mathrm{Al}$-doped $\mathrm{ZnO}$ nanorods shows very fast response and recovery time of $10 \mathrm{~s}$ in comparison to uncoated $\mathrm{ZnO}(20 \mathrm{~min})$ nanorods.
\end{abstract}

Keywords. Electrochemical; aluminium-doped zinc oxide; PVA-coated; UV sensing.

\section{Introduction}

Metal oxide semiconductors have received considerable attention due to their excellent physical and chemical properties (Johnson et al 2001; Vayssieres et al 2001; Kolmakov and Moskovits 2004). Zinc oxide ( $\mathrm{ZnO}$ ), one of the most attractive semiconductor materials for the applications in photonic crystals (Seelig et al 2003), photo-detectors (Lin et al 2008), photodiodes (Chang et al 2012), light emitting diodes (Willander et al 2009), gas sensors (Gupta et al 2010) and solar cells (Beek et al 2004) is attracting enormous attention because of its novel optoelectronic and electrical properties (Chena et al 2009; Ardakani et al 2012). Out of the various applications of metal oxide semiconductors, UV-photodectors are useful in space research, missile warning systems, high flame detection, air quality monitoring, gas sensing, accurate measurement of radiation for the treatment of UV-irradiated skin, etc. (Zhang et al 2009).

Metal oxides having good optical and structural properties also require good electrical properties to be used in electronic devices. $\mathrm{ZnO}$ exhibit $n$-type conductivity due to its native defect of zinc interstitials and oxygen vacancies (Kang et al 2008). Dopant atoms of higher valance elements such as aluminium $(\mathrm{Al})$, indium $(\mathrm{In})$ and gallium $(\mathrm{Ga})$ are used to improve its electrical conductivity (Jin et al 1988). Doping of $\mathrm{Al}$ is preferable, due to its easy incorporation in $\mathrm{ZnO}$ structure, cheap, high abundance and non-toxic nature (Lee and Park 2003; Horwat and Billard 2007; Zhou et al 2007; Caglar et al 2008). Undoped and doped zinc oxide films have been usually grown by various deposition techniques, such as electrospinning (Lotus et al 2010), chemical spray technique

\footnotetext{
*Author for correspondence (saxena.mehta@gmail.com)
}

(Olvera et al 2010), pulsed laser deposition (Kang et al 2004), D.C. magnetron sputtering (Takeda and Fukawa 2004), RF magnetron sputtering (Zhu et al 2000), atomic layer deposition (Luka et al 2011), metal organic chemical vapour deposition (Kim and Kim 2003), molecular beam epitaxy (Sano et al 2004), metal organic vapour phase epitaxy (Ma et al 2004), reactive deposition (Zhenguo et al 2003), spray pyrolysis (Nunes et al 2002), filtered vacuum arc deposition (Gontijoa et al 2012), sol-gel (Armelao et al 2001) and cathodic electrodeposition (Yoshida et al 2004; Postels et al 2008; Jehl et al 2010) on different substrates. In this paper, we have also reported the synthesis of pure and Al-doped $\mathrm{ZnO}$ nanorods by simple electrochemical route. The defects on the surface of nanostructure decrease its UV-sensitivity. Qin et al (2011) reported the improvement in ultraviolet radiation sensitivity of $\mathrm{ZnO}$ nanoparticles by coating with PVA. We report here, enhancement in electrical conductivity upon Al-doping in $\mathrm{ZnO}$. Surface passivation of Al-doped $\mathrm{ZnO}$ nanorods has been carried out with PVA to improve its UV-radiation sensitivity.

\section{Experimental}

Nanorods of $\mathrm{ZnO}$ and $\mathrm{Al}$-doped $\mathrm{ZnO}$ were grown from aqueous solution of zinc nitrate and hexamethylenetetramine (HMT). Aqueous solution of $\mathrm{Zn}\left(\mathrm{NO}_{3}\right)_{2} \cdot 6 \mathrm{H}_{2} \mathrm{O}$ and HMT was prepared using double-distilled water. The solution was stirred constantly. The temperature of the solution was maintained at $80{ }^{\circ} \mathrm{C}$. The two electrodes were lowered in the solution to which a potential ranging from 0.8 to $1 \mathrm{~V}$ was applied by using a D.C. power supply. Indium tin oxide-coated glass plate was used as cathode. The distance between the electrode plates was kept at $10 \mathrm{~mm}$. 1-2 wt\% (Al to 
$\mathrm{ZnO}$ ) aluminium doping in $\mathrm{ZnO}$ were obtained using aluminium nitrate. Pure $\mathrm{ZnO}$ nanorods were prepared by electrodeposition from aqueous solution. Aluminium-doped $\mathrm{ZnO}$ nanorods were also prepared using same technique. Prepared $\mathrm{Al}$-doped $\mathrm{ZnO}$ nanorods were dip-coated with very dilute solution of polyvinyl alcohol $(0.5 \%$ by weight in water) and dried in vacuum. Synthesized materials were structurally characterized by using a Bruker D8 X-ray diffractometer with a high-star 2-d detector. The diffraction pattern was recorded from 20 to $80^{\circ}$. Photoluminescence spectra of Al-doped $\mathrm{ZnO}$ and undoped $\mathrm{ZnO}$ films were also studied using Shimadzu spectrofluorometer RF-5301PC. All the measurements were performed at room temperature in ambient conditions. Size and morphology of the synthesized nanorods were characterized by using dual beam scanning electron microscope (SEM). UV-visible absorption spectra of the synthesized materials were also recorded by using Shimadzu 2401PC spectrophotometer. Electrodes were made by depositing two silver point contacts on top of the films. Current-voltage (I-V) characteristics of samples were measured using a Ketihley-2400 source meter interfaced with computer under darkness and under illumination by a $340 \mathrm{~nm}$ UV LED with an intensity $45.58 \mathrm{~mW} / \mathrm{cm}^{2}$. The area of the photo detectors exposed to UV-light was kept constant $\left(160 \mathrm{~mm}^{2}\right)$ in all the measurements. Response and recovery of the photodetectors were recorded by computer-controlled Keithley-6514 electrometer.

\section{Results and discussion}

$\mathrm{X}$-ray diffraction pattern of the synthesized $\mathrm{ZnO}$ and $\mathrm{Al}$ doped $\mathrm{ZnO}$ nanorods are shown in figure 1. Curves $\mathrm{A}$ and $\mathrm{B}$ in the figure represent $\mathrm{XRD}$ of pure $\mathrm{ZnO}$ and $\mathrm{Al}$-doped
$\mathrm{ZnO}$ nanorods, respectively, in the range of $20-80^{\circ}$. Curve A of figure 1 indicates that all the diffraction peaks correspond to crystalline $\mathrm{ZnO}$ with the hexagonal wurtzite structure (Olvera et al 2010). No characteristic peaks from other impurities are detected. The peak at $34.772 \theta$ value is strongest, corresponding to (002) lattice plane in $\mathrm{ZnO}$. Other lower intensity peaks at $2 \theta$ values of $32.02,36.63,47.89$, $56 \cdot 02,63 \cdot 14$, and $72 \cdot 27$ corresponds to (100), (101), (102), (110), (103) and (004) lattice planes, respectively. Curve B of figure 1 indicates that $\mathrm{Al}$-doped $\mathrm{ZnO}$ also exhibited polycrystalline structure similar to $\mathrm{ZnO}$ hexagonal wurtzite type (JCPDS \#36-1451). In Al-doped ZnO, the intensity of the peak at $34.772 \theta$ value decreases in comparison to undoped $\mathrm{ZnO}$. Peaks at 56.02 and $72.772 \theta$ values which correspond to (110) and (004) planes are missing in Al-doped $\mathrm{ZnO}$. These results indicate that doping of aluminum in $\mathrm{ZnO}$ structure decreases its crystallinity.

$\mathrm{XRD}$ spectra revealed that no peaks due to $\mathrm{Al}$ or any other impurity are observed. This reveals that $\mathrm{Al}$ replaced $\mathrm{Zn}$ from the lattice or $\mathrm{Al}$ segregated to the non-crystalline region in grain boundary (Lee and Park 2003). The formation of stress by the difference in ion size between $\mathrm{Zn}\left(r_{\mathrm{Zn}}^{2+}=0.074 \mathrm{~nm}\right)$ and $\mathrm{Al}\left(r_{\mathrm{Al}}^{3+}=0.054 \mathrm{~nm}\right)$ with doping is known to be responsible for aggravation in $\mathrm{ZnO}$ crystallinity (Zhou et al 2007). As compared to $\mathrm{Zn}^{2+}$, extrinsic $\mathrm{Al}^{3+}$ capture more oxygen due to larger nuclear charge of $\mathrm{Al}^{3+}$ decreases the crystalline and hexagonal structure of the thin films (Horwat and Billard 2007).

The SEM micrographs of undoped and Al-doped $\mathrm{ZnO}$ nanorods are represented in figure 2( $a$ and $b$ ). The average diameter and length of the nanorods are about $100 \mathrm{~nm}$ and $1 \mu \mathrm{m}$, respectively. The insets in figure 2(a and b) shows enlarged images of the nanorods. Some granular structure is observed on the surface of the nanorods in the case of

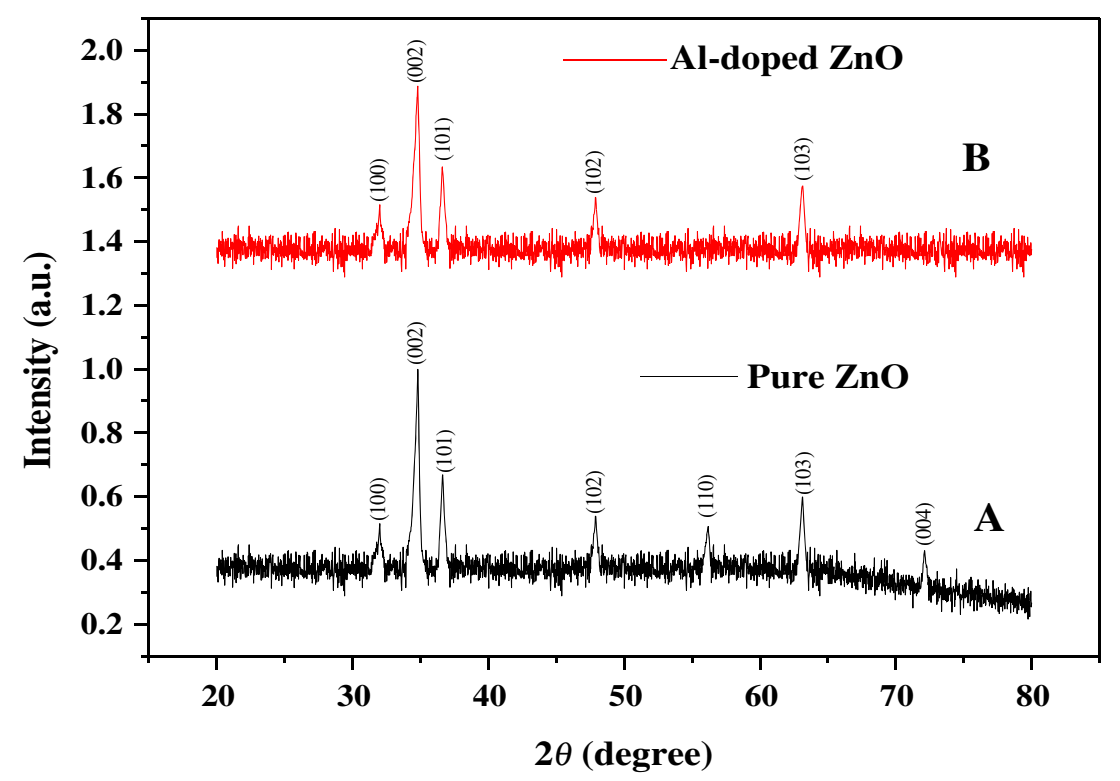

Figure 1. XRD patterns of pure (curve A) and $\mathrm{Al}$-doped $\mathrm{ZnO}$ (curve $\mathrm{B}$ ) nanorods. 


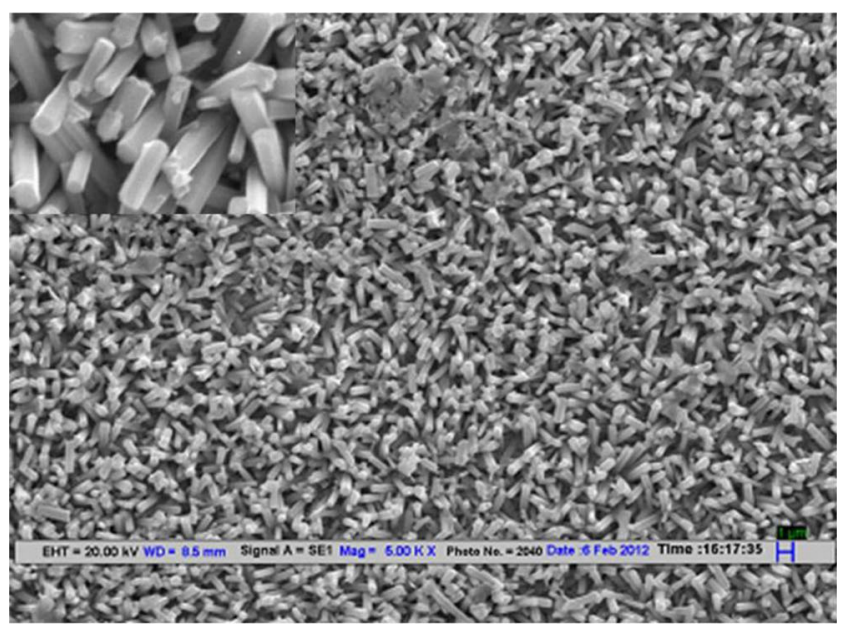

(a)

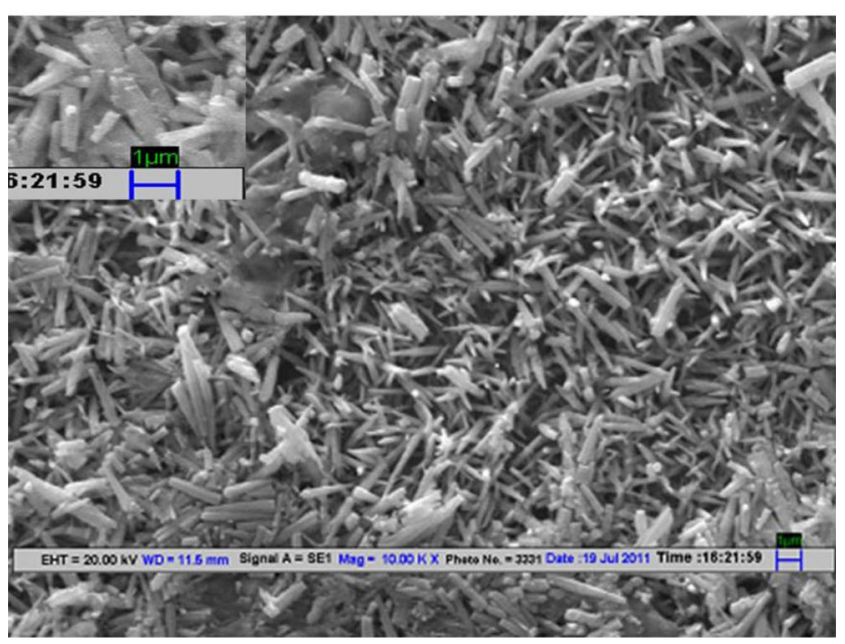

(b)

Figure 2. SEM images of pure and Al-doped $\mathrm{ZnO}$ nanorods synthesized by electrochemical method: (a) SEM micrograph of $\mathrm{ZnO}$ nanorods and (b) SEM micrograph of Al-doped $\mathrm{ZnO}$ nanorods.

aluminium doping as can be seen from figure 2(b). The optical absorption spectra of undoped and $\mathrm{Al}$-doped $\mathrm{ZnO}$ nanorods are shown in figure 3 . It is noted that pure $\mathrm{ZnO}$ nanorods have lower absorbance in visible range of spectrum. The absorbance in visible region of electromagnetic spectrum increases after doping with aluminium in $\mathrm{ZnO}$ structure. This behaviour may be due to the introduction of aluminium defect states within the forbidden bands, which may lead to absorption of incident photon in visible region. The absorption edge of $\mathrm{Al}$-doped $\mathrm{ZnO}$ nanorods shows bathochromic shift with respect to the undoped $\mathrm{ZnO}$. Similar behaviour has also been reported in case of $\mathrm{Mn}$-doped $\mathrm{ZnO}$ films by Shinde et al (2006).

Figure 4(a) shows the photoluminescence (PL) spectra of undoped $\mathrm{ZnO}$ nanorods at different excitation wavelengths. The UV emission with a sharp peak at $387 \mathrm{~nm}$ is originated from excitonic recombination dominating the near band edge emission (Liu et al 2004). The other peaks at $415 \mathrm{~nm}$ and broader peak in the visible region at $550 \mathrm{~nm}$ is associated

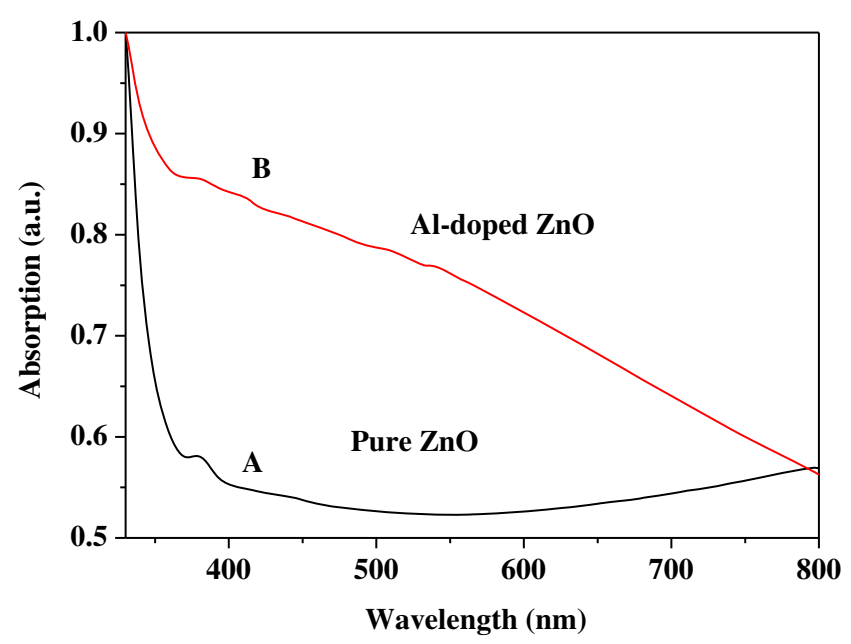

Figure 3. UV-visible absorption spectra of pure $\mathrm{ZnO}$ nanorods (curve A) and Al-doped $\mathrm{ZnO}$ nanorods (curve B).
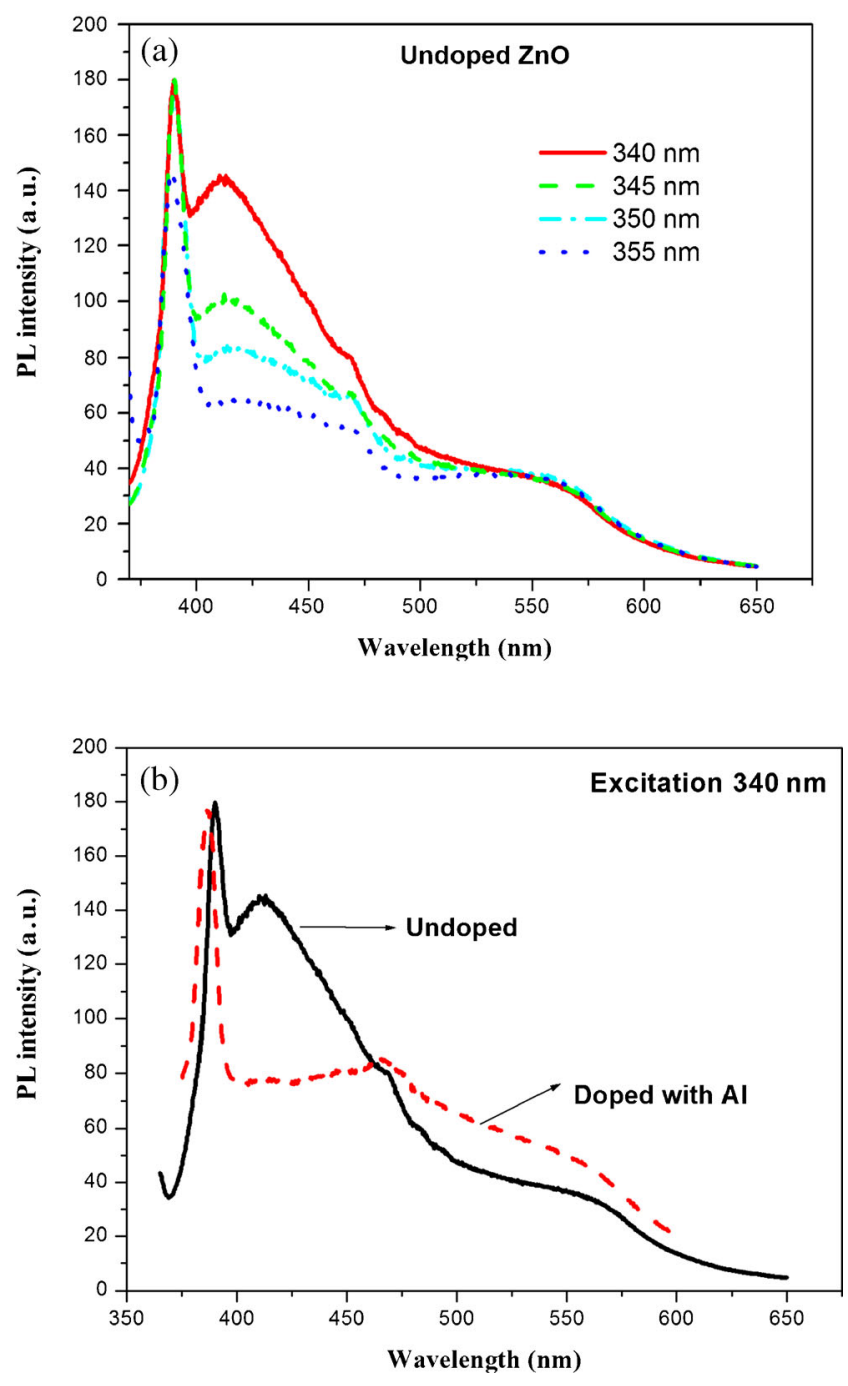

Figure 4. (a) Photoluminescence (PL) spectra of undoped $\mathrm{ZnO}$ films at different excitation wavelengths. (b) Comparison of PL spectra of undoped and Al-doped $\mathrm{ZnO}$ films. 
with the deep level emission due to recombination of photogenerated hole with the electron that belongs to a singly ionized oxygen vacancy and structural defects such as interstitial zinc or oxygen (Liu et al 2004). The peak at $415 \mathrm{~nm}$ $(0.298 \mathrm{eV})$ is more pronounced at higher excitation energies $3.64 \mathrm{eV}(340 \mathrm{~nm})$. From the calculated defect levels in $\mathrm{ZnO}$ films, the defect due to zinc interstitials corresponds to $2.9 \mathrm{eV}$ (Willander et al 2010). The PL peak at $415 \mathrm{~nm}$ is quite close to the calculated defect level due to zinc interstitial. PL spectra of Al-doped and undoped $\mathrm{ZnO}$ at $340 \mathrm{~nm}$ excitation wavelength is depicted in figure 4(b). Introduction of $\mathrm{Al}$ in the synthesis of $\mathrm{ZnO}$ thin films results in the depression of the PL from the defect levels particularly, due to interstitial zinc in $\mathrm{Al}$-doped $\mathrm{ZnO}$ films.

Figure 5( $a$ and $b$ ) shows I-V characteristics of undoped, $\mathrm{Al}$-doped and PVA-coated Al-doped $\mathrm{ZnO}$ nanorods under dark and in UV illumination at room temperature in the
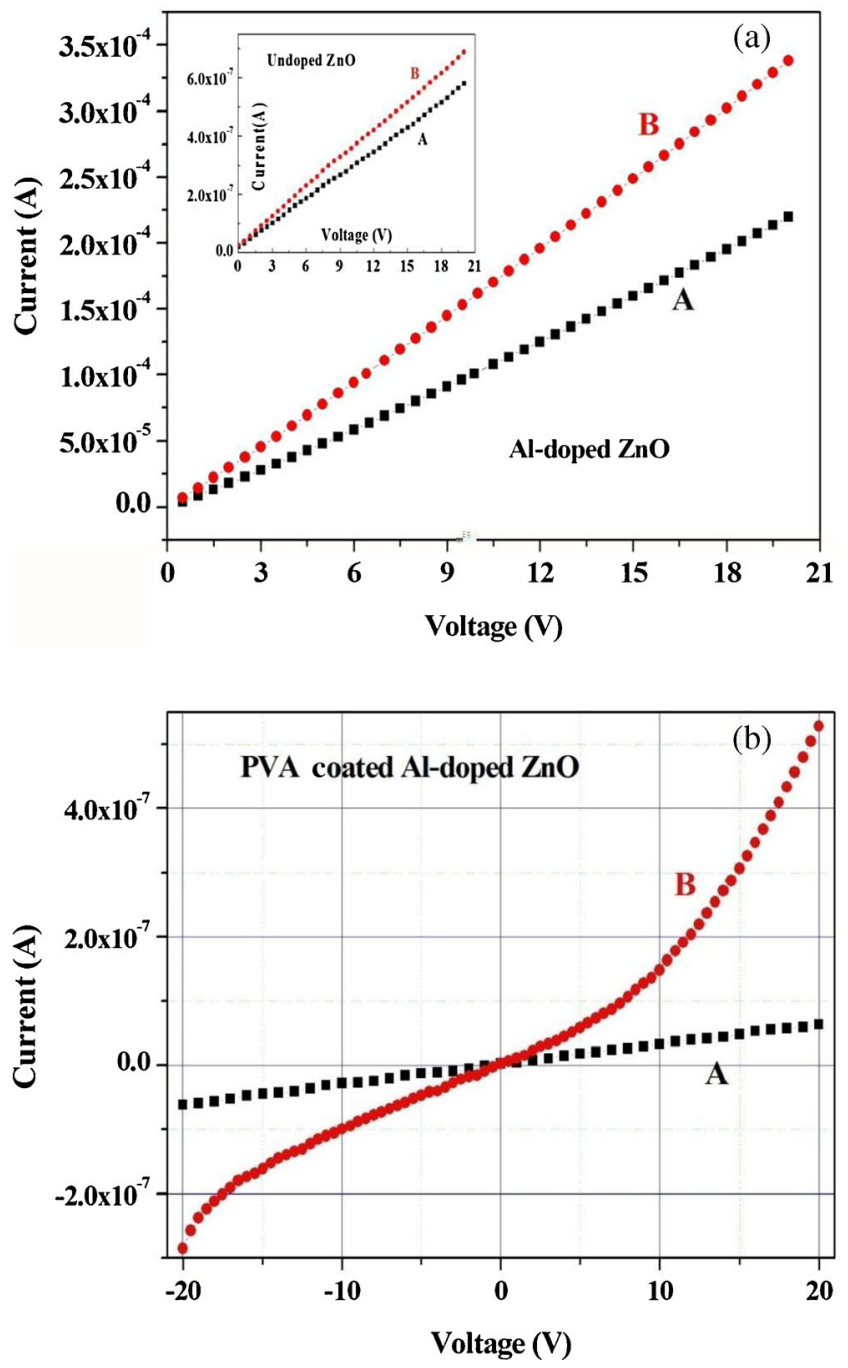

Figure 5. (a) $\mathrm{I}-\mathrm{V}$ curves of $\mathrm{Al}$-doped $\mathrm{ZnO}$ in dark (curve $\mathrm{A}$ ) and UV-light illuminated (curve B); inset: $\mathrm{I}-\mathrm{V}$ curves of pure $\mathrm{ZnO}$ in dark (curve A) and UV-light illuminated (curve B). (b) I-V curves of PVA-coated Al-doped ZnO in dark (curve A) and UV-light illuminated (curve B). voltage range of 0-20 V. Silver contacts were made as electrodes take the current-voltage characteristics. Figure 5(a) and its inset shows $\mathrm{I}-\mathrm{V}$ curve of $\mathrm{Al}-$ doped $\mathrm{ZnO}$ and undoped $\mathrm{ZnO}$ nanorods in dark and under UV-illumination. I-V curves show ohmic behaviour for both the samples. Similar type of ohmic characteristics has also been obtained with gold contacts on pure and $\mathrm{Al}$-doped $\mathrm{ZnO}$ films by Mamat et al (2010). The electrical conductivity of $\mathrm{ZnO}$ nanorods increases upon doping with aluminium. Aluminium doping increases carrier concentration in $\mathrm{ZnO}$ nano structure because aluminium has one more valance $e^{-}$than zinc. Hence aluminium doping in $\mathrm{ZnO}$ nanostructure effectively improve its electrical properties. I-V characteristic shows that the current intensity for both the samples increase under UV-light illumination with respect to its dark value. The increase in photocurrent can be explained by photoexcitation of electrons from valance band to the conduction band of the material.

Qin et al (2011) reported that most of the UV-generated carriers in the $\mathrm{ZnO}$ are trapped by defects during transportation to the terminals. To overcome this effect, Al-doped $\mathrm{ZnO}$ are dip-coated with dilute solution of polyvilyl alcohol to reduce the surface defects. The I-V characteristics of PVA coated $\mathrm{Al}$-doped $\mathrm{ZnO}$ in dark and under UV-illumination is shown in figure 5(b). Enhancement in photo-response is observed in PVA-coated Al-doped $\mathrm{ZnO}$ nanorods. This indicates that PVA acts as effective surface passivation material to improve the photo-sensitivity of Al-doped $\mathrm{ZnO}$. Hence, PVA-coated Al-doped $\mathrm{ZnO}$ nanorods act as good UV sensing materials. Further, the UV response of $\mathrm{Al}$-doped $\mathrm{ZnO}$ and PVA-coated Al-doped $\mathrm{ZnO}$ films are studied. The response and recovery times for PVA-coated $\mathrm{Al}$-doped $\mathrm{ZnO}$ nanorods films were studied for three $\mathrm{Al}$ doping concentrations (1, 1.5 and $2 \mathrm{wt} \%)$. Figure $6(\mathrm{a}-\mathrm{d})$ shows the response and recovery time of Al-doped $\mathrm{ZnO}$ and PVA-coated Al-doped $\mathrm{ZnO}$ films to $365 \mathrm{~nm}$ UV light. The response and recovery times are relatively fast for PVA-coated $\mathrm{Al}$-doped $\mathrm{ZnO}$ nanorods (figure 6(b-d)) as compared to simply Al-doped $\mathrm{ZnO}$ (figure 6a). When both the photodetectors are illuminated by $365 \mathrm{~nm}$ UV light, the electrical resistance decreases sharply. On turning off UV light resistance returns to its initial value with a very fast recovery time of almost $10 \mathrm{~s}$ in case of PVA-coated Al-doped $\mathrm{ZnO}$ nanorods, whereas recovery, in case of uncoated $\mathrm{Al}$-doped $\mathrm{ZnO}$ nanorods is very slow. Multiple experiments were performed and similar results were obtained with an accuracy of $7-10 \%$ for time constants. There was not much difference in the response times ( $\sim 25-30$ s) however, the recovery times were found to be much larger in the case of 1 and $2 \mathrm{wt} \% \mathrm{Al}$ doping as compared to $1.5 \mathrm{wt} \% \mathrm{Al}$ doping concentration as depicted in figure $6(\mathrm{~b}-\mathrm{d})$. The on/off ratio in the case of $1,1.5$ and $2 \mathrm{wt} \%$ Al-doped $\mathrm{ZnO}$ films were found to be approximately 6,4 and $1 \Omega$, respectively, which indicates that the sensitivity of $1 \mathrm{wt} \% \mathrm{Al}$-doped $\mathrm{ZnO}$ film is more than that for higher concentrations of $\mathrm{Al}$ doping. On the other hand, the recovery from the on to off state of 1 and $2 \mathrm{wt} \%$ Al-doped $\mathrm{ZnO}$ films were found to be slower as compared to $1.5 \mathrm{wt} \%$ Al-doped 


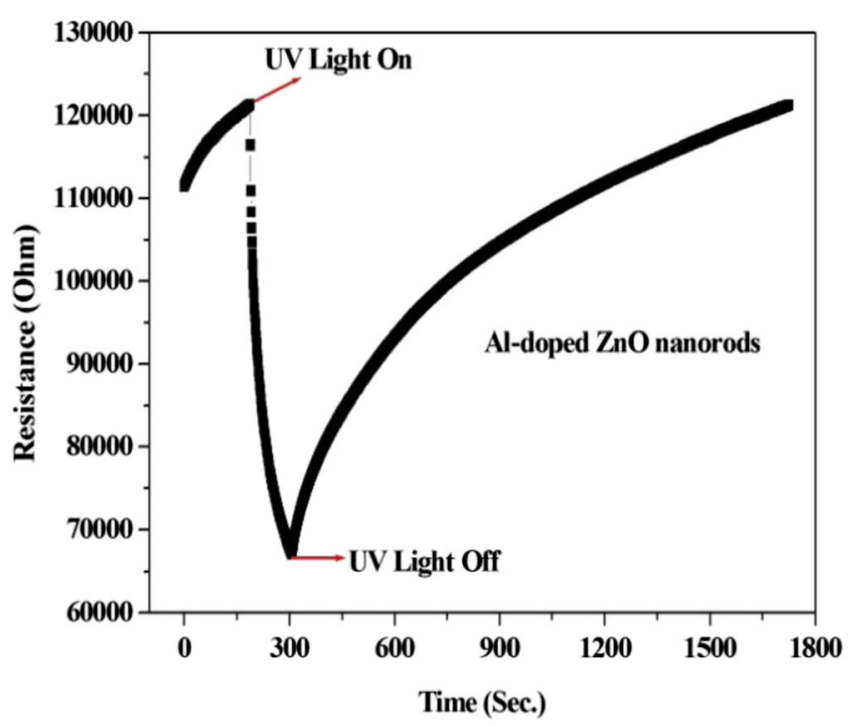

(a)

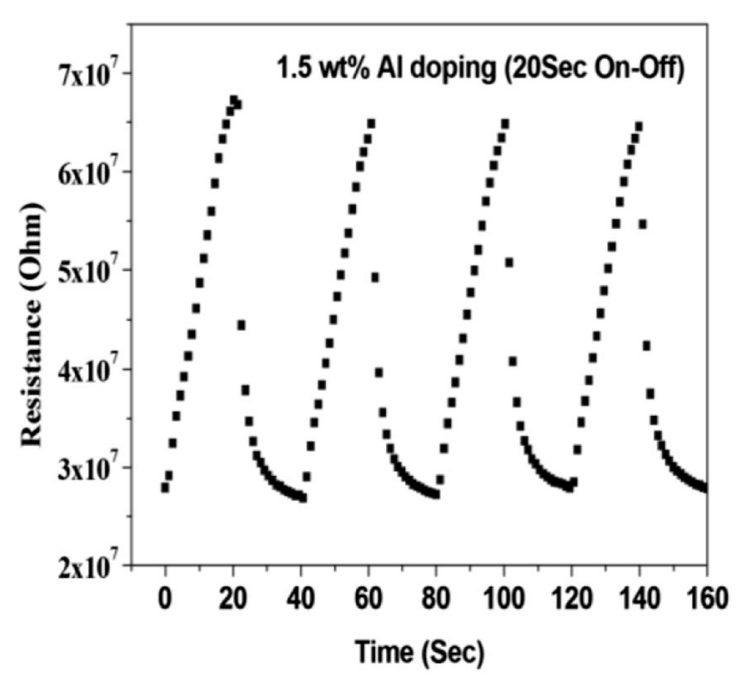

(c)

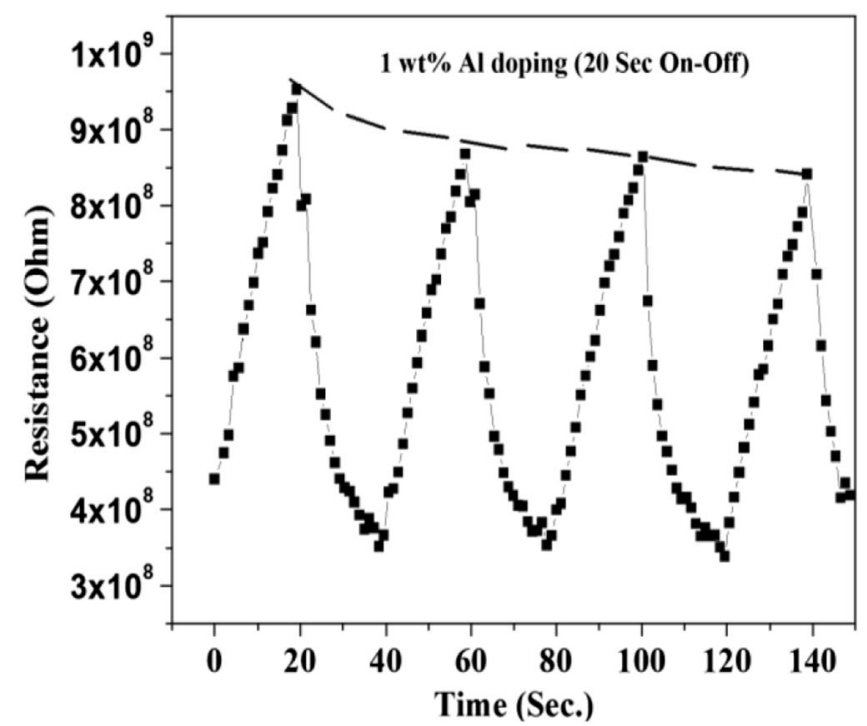

(b)

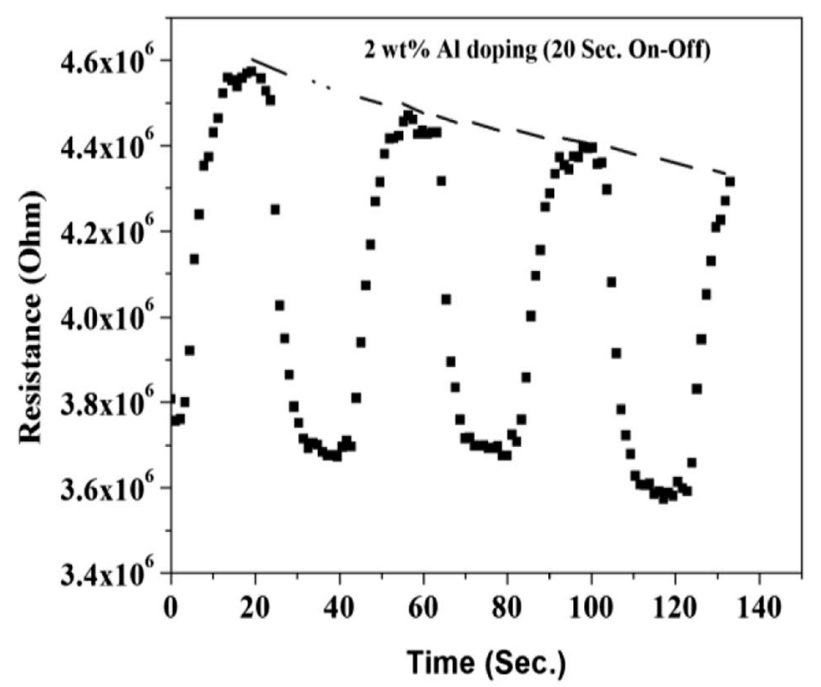

(d)

Figure 6. UV-response and recovery for Al-doped $\mathrm{ZnO}$ nanorods based $\mathrm{UV}$ photo-detector (a) and PVA-coated Al-doped ZnO nanorods based UV photo-detector at $20 \mathrm{~s}$ on/off time scale for (b) 1 (c) 1.5 and (d) $2 \mathrm{wt} \%$ Al doping, respectively.

ZnO. ZnO films prepared with higher Al doping concentrations $(>2 \mathrm{wt} \%)$ were found to be non-uniform and showed irregular response to UV light. So, the optimum $\mathrm{Al}$ doping concentration was found to be $1.5 \mathrm{wt} \%$. The effect on photoresponse of the thickness of the PVA coating on Al-doped $\mathrm{ZnO}$ film was also studied. When the thickness of the PVA coating on Al-doped $\mathrm{ZnO}$ was increased by increasing the concentration of PVA in water ( $>0.5 \mathrm{wt} \%$ ) that is used for dip coating, the sheet resistance of the films increased and photo-conducting effect was suppressed.

Photodetection mechanism is as follows. Initially, oxygen molecules adsorbed on the surface of $\mathrm{ZnO}$ nanorods decrease the carriers density by trapping free electrons, $\mathrm{O}_{2}(\mathrm{~g})+e^{-} \rightarrow \mathrm{O}_{2}^{-}(\mathrm{ad})+e^{-} \rightarrow \mathrm{O}_{2}^{2-}$ (ad). This leads to the formation of a depletion region near the surface, which significantly decreases the conductance. The UV response time is governed by adsorption and desorption of $\mathrm{O}_{2}$ molecules on the surface (Chai et al 2009; Lupan et al 2009). After the photosensor is illuminated by UV light, the electron-hole $\left(e^{-}-h^{+}\right)$pairs are generated, $\left(h v \rightarrow e^{-}-h^{+}\right)$. The holes $\left(h^{+}\right)$migrate to the surface to discharge the chemisorbed oxygen ions and lowering the depletion layer near the surface $\left(\mathrm{O}_{2}^{2-}(\mathrm{ad})+h^{+} \rightarrow \mathrm{O}_{2}^{-}(\mathrm{ad})+h^{+} \rightarrow \mathrm{O}_{2}(\mathrm{~g})\right)$. The remaining unpaired electrons contribute to the current. After UV light is turned off, the holes concentration is lower than that of electrons in Al-doped $\mathrm{ZnO}$ nanorods. However, $h^{+}$recombines with $e^{-}$, simultaneously oxygen molecules readsorb on the surface and capture free electrons. This results in a decrease 
in the conductance value. This fast response and recovery in case of PVA-coated Al-doped $\mathrm{ZnO}$ nanorods may be because of the surface passivation effect of PVA. Hence, PVA-coated $\mathrm{Al}$-doped $\mathrm{ZnO}$ can be used as good UV sensing material.

\section{Conclusions}

Zinc oxide nanorods (undoped and aluminium-doped) have been synthesized by fast and easy electrochemical method. Coating of aluminum-doped $\mathrm{ZnO}$ nanorods with PVA shows enhanced UV sensitivity. PVA-coated Al-doped $\mathrm{ZnO}$ nanorods have fast response and recovery time in comparison to uncoated $\mathrm{Al}$-doped $\mathrm{ZnO}$ nanorods. These results indicate that PVA-coated $\mathrm{Al}$-doped $\mathrm{ZnO}$ nanorods can be used to fabricate low cost and sensitive UV sensor.

\section{Acknowledgements}

The authors are thankful to Dr Ashok K Chauhan, Chairman, Amity University, Noida, UP, for his continuous encouragements. Authors are also thankful to Ms Omita Nanda and Ms Nidhi Gupta for their technical help in the experimental work.

\section{References}

Ardakani A G, Pazoki M, Bahrampour S M M A R and Taghavinia N 2012 Appl. Surf. Sci. 2585405

Armelao L, Fabrizio M, Gialaneela S and Zordan F 2001 Thin Solid Films 39490

Beek W J E, Wienk M M and Janssen R A J 2004 Adv. Mater. 16 1009

Caglar M, Ilican S, Caglar Y and Yakuphanoglu F 2008 J. Mater. Sci.: Mater. Electron. 19704

Chai G, Lupan O, Chow L and Heinrich H 2009 Sens. Actuators A 150184

Chang S J, Weng W Y, Hsu C L, Hsueh T J, Hung F Y, Wu S L and Dai B T 2012 Nanotechnol. IEEE Trans. 11127

Chena K J, Hungb F Y, Changa S J and Young S J 2009 J. Alloys Compnd. 479674

Gontijoa L C, Cunhab A G and Nascentec P A P 2012 Mater. Sci. Eng. B 1771783

Gupta S K, Joshi A and Kaur M 2010 J. Chem. Sci. 12257

Horwat D and Billard A 2007 Thin Solid Films 5155444

Jehl Z, Rousset J, Donsanti F, Renou G, Naghavi N and Lincot D 2010 Nanotechnology 21395603
Jin Z-C, Hamberg I and Granqvist C G 1988 J. Appl. Phys. 645117 Johnson R S, Lucovsky G and Baumvol I $2001 \mathrm{~J}$. Vac. Sci. Technol. A 191353

Kang H S, Kang J S, Kim J W and Lee S Y 2004 J. Appl. Phys. 95 1246

Kang H S, Kim G H, Lim S H, Chang H W, Kim J H and Lee S Y 2008 Thin Solid Films 5163147

Kim K-S and Kim H W 2003 Physica B 328368

Kolmakov A and Moskovits M 2004 Ann. Rev. Mater. Res. 34151

Lee J H and Park B O 2003 Thin Solid Films 42694

Lin Y-Y, Chen C-W, Yen W-C, Su W-F, Ku C-H and Wu J-J 2008 Appl. Phys. Lett. 92233301

Liu X, Wu X, Cao H and Chang R P H 2004 J. Appl. Phys. 953141

Lotus A F, Kang Y C, Walker J I, Ramsier R D and Chase G G 2010 Mater. Sci. Eng. B 16661

Luka G, Wachnicki L, Witkowski B S, Krajewski T A, Jakiela R, Guziewicz E and Godlewski M 2011 Mater. Sci. Eng. B 176 237

Lupan O, Chow L and Chai G 2009 Sens. Actuators B 141511

Ma Y et al 2004 J. Appl. Phys. 956268

Mamat M H, Sahdan M Z, Khusaimi Z, Ahmed A Z, Abdullah S and Rusop M 2010 Optic. Mater. 32696

Nunes P, Fortunato E, Tonello P, Fernandes F B, Vilarinho P and Martins R 2002 Vacuum 64281

Olvera M L, Maldonado A, Pérez J V and Feri O S 2010 Mater. Sci. Eng. B 17442

Postels B, Bakin A, Wehmann H-H, Suleiman M, Weimann T, Hinze P and Waag A 2008 Appl. Phys. A 91595

Qin L, Shing C, Sawyer S and Dutta P S 2011 Optic. Mater. 33359

Sano M, Miyamoto K and Kato H 2004 J. Appl. Phys. 955527

Seelig E W, Tang B, Yamilov A, Cao H and Chang R P H 2003 Mater. Chem. Phys. 80257

Shinde V R, Gujar T P, Lokhande C D, Mane R S and Han S-H 2006 Mater. Chem. Phys. 96326

Takeda S and Fukawa M 2004 Thin Solid Films 468234

Vayssieres L, Keis K, Lindquist S-E and Hagfeldt A 2001 J. Phys. Chem. B 1053350

Willander M et al 2009 Nanotechnology 20332001

Willander M, Nur O, Sadaf J R, Qadir M I, Zaman S, Zainelabdin A, Bano N and Hussain I 2010 Materials 32643

Yoshida T, Komatsu D, Shimokawa N and Minoura H 2004 Thin Solid Films 451-452 166

Zhang T C, Guo Y, Mei Z X, Gu C Z and Du X L 2009 Appl. Phys. Lett. 94113508

Zhenguo J, Kun L, Chengxing Y, Ruixin F and Zhizhen Y 2003 J. Cryst. Growth 253246

Zhou H-M, Yi D-Q, Yu Z-M, Xiao L-R and Li J 2007 Thin Solid Films $\mathbf{5 1 5} 6909$

Zhu F, Zhang K, Guenther E and Jin C S 2000 Thin Solid Films 363 314 